\title{
Comparison of Glycated Albumin (GA) and Glycated Hemoglobin (HbA1c) in Type 2 Diabetic Patients: Usefulness of GA for Evaluation of Short-term Changes in Glycemic Control
}

\author{
SATOMI TAKAHASHI*, HIROSHI UCHINO*, TOMOAKI SHIMIZU*, AKIO KANAZAWA*, \\ YOSHIFUMI TAMURA*, KEN SAKAI*, HIROTAKA WATADA*, TAKAHISA HIROSE*, RYUZO KAWAMORI* \\ AND YASUSHI TANAKA*,** \\ *Metabolism and Endocrinology, Department of Medicine, Juntendo University School of Medicine, 2-1-1 Hongo, Bunkyo-ku, Tokyo \\ 113-8421, Japan \\ **Metabolism and Endocrinology, Department of Medicine, St. Marianna University School of Medicine, 2-16-1 Sugao, Miyamae-ku, \\ Kawasaki, Kanagawa 216-8511, Japan
}

\begin{abstract}
We studied the cross-sectional relationship between GA and HbA1c in 142 type 2 diabetic patients who had an $\mathrm{HbA} 1 \mathrm{c}$ level $<7.5 \%$ for at least one year without fluctuation by more than $0.5 \%$. We also followed the changes of GA and $\mathrm{HbA} 1 \mathrm{c}$ in 18 type 2 diabetic patients for 16 weeks as they progressed from untreated severe hyperglycemia $(\mathrm{HbA} 1 \mathrm{c} \geq 9.0 \%)$ to good glycemic control (HbAlc $\leq 6.5 \%)$ by intensive insulin treatment. The annual mean levels of GA and $\mathrm{HbA} 1 \mathrm{c}$ in the stably controlled patients showed a weak, but significant, correlation $(\mathrm{r}=0.23, \mathrm{p}<0.001)$ in the 142 diabetic patients. However, the GA/HbA1c ratio ranged widely from 2.0 to 4.0 showing a normal distribution $(2.9 \pm 0.34$, $\mathrm{M} \pm \mathrm{SE}$ ), although patients with conditions affecting albumin turnover or RBC lifespan were excluded from the study. The GA/HbA1c ratio was significantly higher when patients were in hyperglycemic than when glycemic control was good $(3.5 \pm 0.15$ vs. $2.9 \pm 0.07, \mathrm{M} \pm \mathrm{SE}, \mathrm{p}<0.01)$. GA decreased more rapidly than HbA1c during intensive insulin therapy, but the percent reduction of $\mathrm{HbAlc}$ eventually corresponded with that of GA by 16 weeks after the start of treatment. These results demonstrate that, although unknown influences on GA or HbAlc may exist, GA may be a useful marker for monitoring short-term variations of glycemic control during treatment of diabetic patients.
\end{abstract}

Key words: Glycated albumin, Glycated hemoglobin, Glycation product, Glycemic control, Diabetes mellitus

(Endocrine Journal 54: 139-144, 2007)

THE stable fraction of glycated hemoglobin (HbAlc) is routinely measured in the majority of patients with diabetes around the world, since $\mathrm{HbAlc}$ reflects mean glycemia over the preceding 2-3 months [1]. Thus, it is not only used to determine whether a patient's metabolic control has reached and been maintained within the target range, but also to estimate the risk of chronic diabetic complications in each patient $[2,3]$. However, HbA1c may not be suitable for the evaluation of shortterm variations of glycemic control because of the long

Received: June 15, 2006

Accepted: November 6, 2006

Correspondence to: Yasushi TANAKA, M.D., Ph.D., Metabolism and Endocrinology, Department of Medicine, St. Marianna University School of Medicine, 2-16-1 Sugao, Miyamae-ku, Kawasaki, Kanagawa 216-8511, Japan lifespan of erythrocytes (120 days).

Because the turnover of human serum albumin is much more rapid (half-life of 15-20 days) than that of hemoglobin, the measurement of glycated albumin (GA) provides an index of glycemic control over a shorter period of time ( 2 weeks) than measurement of HbA1c [4-6]. However, the characteristics of GA have not been compared with those of $\mathrm{HbAlc}$ in a cross-sectional analysis, and there has been no comparison between the changes of HbA1c and GA during longitudinal follow-up from untreated hyperglycemia to a well-controlled state by drug therapy, nor any assessment of the correlation between these parameters during severe hyperglycemia and after improvement in diabetic patients. Thus, we have no information on how to actually use GA as a parameter of glycemic 
control in diabetic patients during treatment.

GA was initially evaluated by high-performance liquid chromatography (HPLC) [7]. Recently, a new enzymatic method of determining GA was developed, and was confirmed to have sufficient accuracy and a good correlation with the conventional HPLC method [8]. Since this method can be employed in an autoanalyzer, rapid and multiple determinations can be performed. In this study, we first performed a crosssectional comparison of the 1-year mean values of GA, $\mathrm{HbA} 1 \mathrm{c}$, and the GA/HbA1c ratio from at least 5 simultaneous measurements in type 2 diabetic patients under stable glycemic control for at least one year. Second, we longitudinally evaluated and compared the changes of GA and $\mathrm{HbAlc}$ by periodical simultaneous measurement in type 2 diabetic patients during progression from untreated severe hyperglycemia to a wellcontrolled state over 16 weeks by lifestyle modification and intensive insulin treatment.

\section{Materials and Methods}

\section{Subjects}

\section{Study 1}

A total of 252 patients with type 2 diabetes were retrospectively recruited from the outpatients of Juntendo University Hospital. GA and HbAlc were simultaneously measured at least 5 times in 2005 and HbAlc was constantly $\leq 7.5 \%$ with less than $0.5 \%$ fluctuation during a period of at least one year without drug therapy or without any changes of drug treatment. Among them, patients with anemia, diabetic nephropathy, chronic liver disease, malignancy, thyroid disease, or pregnancy and patients on steroid treatment were excluded. From the remaining 198 patients, 1) those not taking anti-diabetic drugs $(\mathrm{n}=30), 2)$ those using nateglinide or $\alpha$-glucosidase inhibitor alone $(n=48)$, $3)$ those taking sulfonylureas alone $(n=29)$, and 4) those using rapid-acting insulin (insulin aspart or lispro) with or without NPH insulin or insulin glargine and no oral anti-diabetic agents $(\mathrm{n}=35)$ were selected $(\mathrm{n}=142)$. The annual mean values of GA, HbA1c, and the GA/HbAlc ratio were calculated, and were compared among the groups.

\section{Study 2}

A total of 28 patients with untreated type 2 diabetes who had no anemia, renal disease, liver dysfunction, cancer, thyroid disease, pregnancy, or steroid treatment were recruited from the outpatients of Juntendo University Hospital. Their diabetes had been untreated for at least one year from the time of detection at a general health check-up due to their unawareness of hyperglycemic signs and symptoms, and they all had severe hyperglycemia $(\mathrm{HbA} 1 \mathrm{c} \geq 9 \%)$ at the first visit. All patients started intensive insulin treatment with rapidacting insulin (insulin aspart or insulin lispro) three times daily (with or without NPH insulin or insulin glargine before bedtime), while GA and $\mathrm{HbAlc}$ were simultaneously measured at intervals for 16 weeks. Among them, 18 patients reached good glycemic control $(\mathrm{HbA} 1 \mathrm{c} \leq 6.5 \%)$ at 16 weeks after starting insulin treatment, and the time course of GA and $\mathrm{HbAlc}$ changes was evaluated in this group.

\section{Measurement of GA and HbAlc}

GA was determined by an enzymatic method using a liquid chemistry system (GA assay, Asahi Kasei Corp., Tokyo, Japan) in a clinical autoanalyzer [8]. This assay system consisted of the following three steps: 1) a glycated amino assay for glycated albumin using proteinase, ketoamine oxidase, and peroxidase, 2) an albumin assay, and 3) calculation of percentage of glycated albumin in total albumin. HbAlc was measured with an automated HPLC analyzer (723Ghb III, TOSOH Corp., Tokyo, Japan), which combined preincubation step to remove the unstable fraction (preincubation at $50^{\circ} \mathrm{C}$ for 1.5 min at $\mathrm{pH} 3.0$ ) with HPLC for specific measurement of the stable fraction using a calibration standard from the Japan Diabetes Society (JDS).

\section{Statistical analysis}

Data are presented as the mean \pm SE. The significance of differences in clinical parameters among the four groups in study 1 was examined by one-way ANOVA and Bonferroni's multiple comparison tests. In study 2 , the comparison of clinical parameters between baseline and after 16 weeks of insulin treatment and comparison of the percent decrease of GA or $\mathrm{HbA} 1 \mathrm{c}$ during treatment was done by the paired t-test and Student's t-test, respectively. Changes of the GA/ $\mathrm{HbA} 1 \mathrm{c}$ ratio during 16 weeks of insulin treatment were examined by the paired t-test. 
Table 1. Comparison of annual mean values of GA, HbAlc, and GA/HbAlc

\begin{tabular}{lccrc}
\hline & Group 1 & Group 2 & Group 3 & Group 4 \\
\cline { 2 - 5 } Treatment & diet & a-GI or nateglinide alone & SU alone & $\begin{array}{c}\text { rapid acting inslin } \\
(+/- \text { NPH or glargine) }\end{array}$ \\
\hline N (M/F) & $30(19 / 11)$ & $48(28 / 20)$ & $29(19 / 10)$ & $35(22 / 13)$ \\
Age (yr) & $68 \pm 1.8$ & $67 \pm 1.8$ & $68 \pm 1.6$ & $61 \pm 2.8$ \\
GA (\%) & $17.7 \pm 0.39^{* *,++}$ & $18.8 \pm 0.42$ & $19.9 \pm 0.41$ & $20.3 \pm 0.47$ \\
HbA1c (\%) & $6.2 \pm 0.08^{* *,+}$ & $6.5 \pm 0.12 * *$ & $6.8 \pm 0.09$ & $7.1 \pm 0.20$ \\
GA/HbA1c & $2.9 \pm 0.32$ & $2.9 \pm 0.35$ & $2.9 \pm 0.32$ & $2.9 \pm 0.35$ \\
\hline
\end{tabular}

$\alpha$-GI: alpha glucosidase inhibitor, SU: sulfonyl urea, ${ }^{* *} \mathrm{p}<0.01$ vs. Group $4,{ }^{+} \mathrm{p}<0.05$ vs. Group $3,{ }^{++} \mathrm{p}<0.01$ vs. Group 3

\section{Results}

\section{Study 1}

The clinical parameters and the annual mean values of $\mathrm{GA}, \mathrm{HbAlc}$, and the $\mathrm{GA} / \mathrm{HbA} 1 \mathrm{c}$ ratio are shown in Table 1. No gender differences were noted among the four groups. The mean baseline age of group 4 was younger, but there were no significant differences among the groups. The annual mean values of GA and HbA1c were significantly lower in group 1 than in group 3 or group 4, and the annual mean $\mathrm{HbAlc}$ level was also significantly lower in group 2 than in group 4 . However, the annual mean $\mathrm{GA} / \mathrm{HbAlc}$ ratio did not differ significantly among the four groups (mean value: 2.9). When combined analysis of the four groups was performed, GA and HbAlc showed a weak, but significant, correlation $(\mathrm{GA}=5.3+2.18 \times \mathrm{HbA} 1 \mathrm{c}, \mathrm{r}=0.23$, $\mathrm{p}=0.0004)$. The actual $\mathrm{GA} / \mathrm{HbA} 1 \mathrm{c}$ ratio values were distributed over a wide range from 2.0 to 4.0 , as shown in Fig. 1. The lowest range was from 2.0 to $<2.2$, and the highest range was from 3.8 to $<4.0$. This ratio showed a normal distribution, and the most common range was from 2.8 to $<3.0$.

\section{Study 2}

Comparison of GA, HbAlc, and the GA/HbAlc ratio values at baseline and 16 weeks after the start of intensive insulin therapy is shown in Table 2. Although the BMI was not altered by treatment, both GA and $\mathrm{HbA} 1 \mathrm{c}$ decreased significantly. The GA/HbA1c ratio was also significantly lower at 16 weeks than at baseline. The profile of the percent decease of GA and $\mathrm{HbA} 1 \mathrm{c}$ during 16 weeks of treatment is shown in Fig. 2 . From as early as 2 weeks, GA showed a significantly larger percent decrease than $\mathrm{HbAlc}$, and this differ-
(\%)

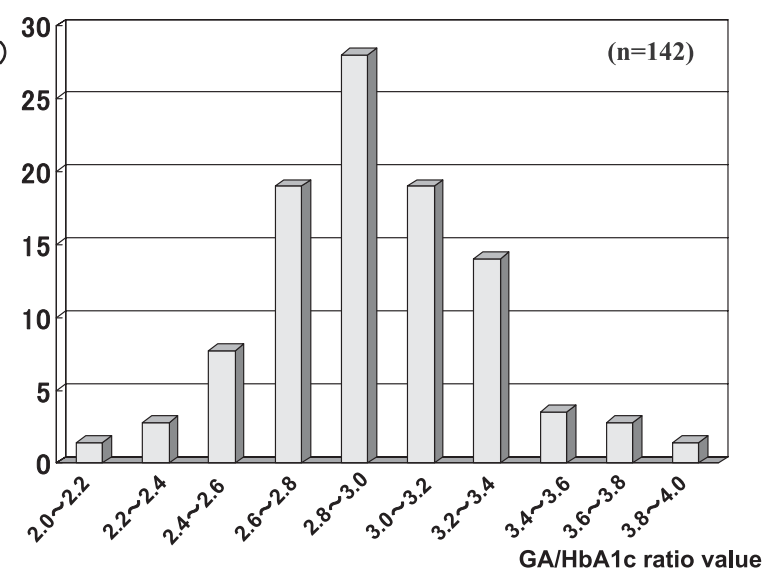

Fig. 1. Distribution of the $\mathrm{GA} / \mathrm{HbA} / \mathrm{c}$ ratio in diabetic patients The range of the ratio was from $[2.0 \leq$ to $<2.2]$ up to $[3.8 \leq$ to $<4.0]$.

Table 2. Comparison between GA and $\mathrm{HbA} 1 \mathrm{c}$ at baseline and after 16 weeks of treatment

\begin{tabular}{lrc}
\hline & Baseline & 16 weeks \\
\hline Age $(\mathrm{yr})$ & \multicolumn{3}{c}{$50 \pm 3.8$} \\
Sex $(\mathrm{M} / \mathrm{F})$ & \multicolumn{3}{c}{$13 / 5$} \\
BMI $\left(\mathrm{kg} / \mathrm{m}^{2}\right)$ & $22.2 \pm 1.17$ & $22.6 \pm 1.01$ \\
GA $(\%)$ & $43.2 \pm 2.85$ & $16.9 \pm 0.39^{* *}$ \\
HbA1c $(\%)$ & $12.1 \pm 0.41$ & $5.82 \pm 0.11^{* *}$ \\
GA/HbA1c & $3.5 \pm 0.15$ & $2.9 \pm 0.07^{* *}$ \\
\hline
\end{tabular}

$* * \mathrm{p}<0.01$ vs. Baseline

ence persisted until week 16 when the percent decrease of two parameters reached a similar level. As shown in Fig. 3, the $\mathrm{GA} / \mathrm{HbA} \mathrm{lc}$ ratio decreased during the initial 8 weeks of treatment and reached its nadir at 8 weeks, after which it gradually increased until 16 weeks. 


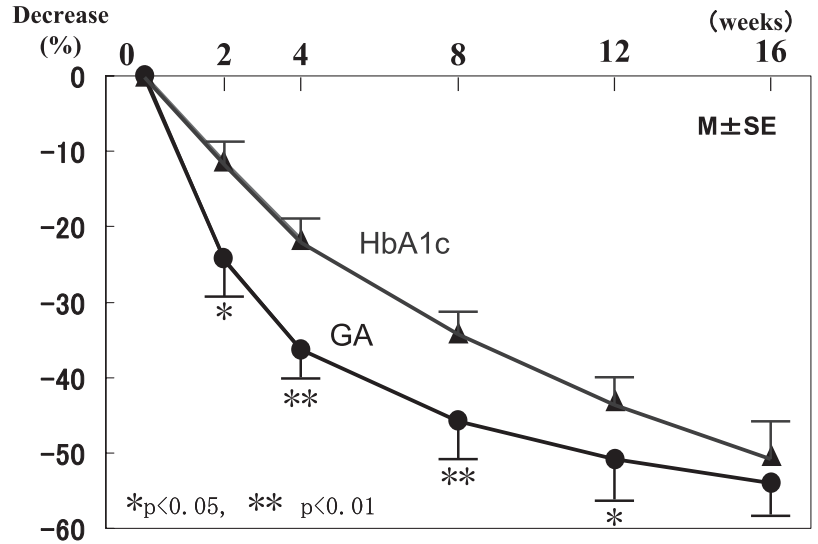

Fig. 2. Time course of the percent decrease of GA and HbAlc during intensive insulin treatment

Data are shown as the mean $\pm \mathrm{SE}, * \mathrm{p}<0.05, * * \mathrm{p}<0.01$ vs. HbA1c.

\section{Discussion}

The present study demonstrated that GA and $\mathrm{HbA} 1 \mathrm{c}$ were significantly correlated in patients with type 2 diabetes who had an $\mathrm{HbA} 1 \mathrm{c}$ level below $7.5 \%$ with less than $0.5 \%$ variation for at least one year. However, the $\mathrm{GA} / \mathrm{HbA} 1 \mathrm{c}$ ratio ranged widely from 2.0 to 4.0 , showing a normal distribution and a mean value of 2.9 (Fig. 1). The mean value of the $\mathrm{GA} / \mathrm{HbA} 1 \mathrm{c}$ ratio did not differ among the 4 groups irrespective of their treatment for diabetes (Table 1). We also showed that the mean $\mathrm{GA} / \mathrm{HbA} 1 \mathrm{c}$ ratio was significantly higher in hyperglycemic patients than after good glycemic control was achieved in the longitudinal investigation (Table 2). Furthermore, GA was decreased more rapidly than $\mathrm{HbA} 1 \mathrm{c}$ by intensive insulin therapy, although the percent decrease of HbAlc was similar to that of GA at 16 weeks after starting insulin treatment (Fig. 2). Consistent with these results, the $\mathrm{GA} / \mathrm{HbAlc}$ ratio decreased during the initial 8 weeks of the therapy to reach its nadir after 8 weeks, and then gradually increased until 16 weeks (Fig. 3).

Both GA and HbA1c are products of non-enzymatic glycation, so diseases or drugs influencing the serum albumin turnover or RBC lifespan may affect their formation, including severe liver or kidney disease, thyroid disease, anemia, malnutrition, malignancy, pregnancy, and steroid therapy. Accordingly, patients with these conditions were excluded from the present study, and the coefficient of variation of the GA/ $\mathrm{HbA} 1 \mathrm{c}$ ratio was $<5 \%$ in every patient. However, the

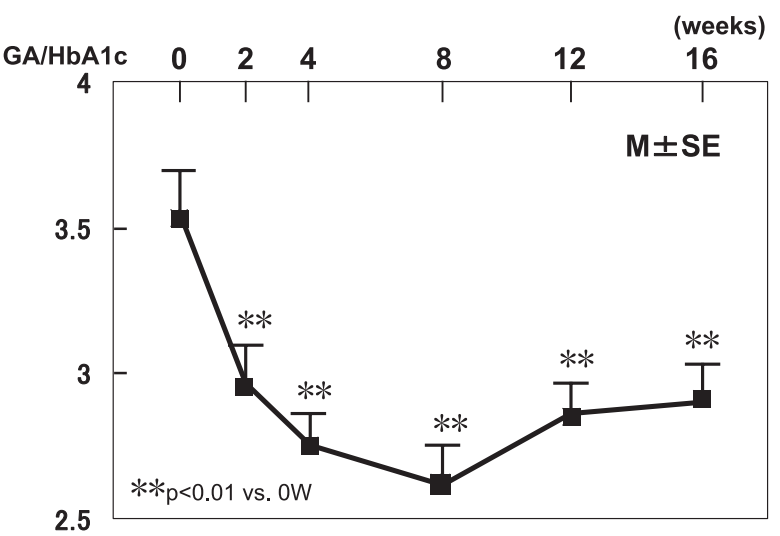

Fig. 3. Changes of the $\mathrm{GA} / \mathrm{HbA} 1 \mathrm{c}$ ratio during intensive insulin treatment

Data are shown as the mean $\pm \mathrm{SE}, * * \mathrm{p}<0.01$ vs. $0-\mathrm{W}$.

$\mathrm{GA} / \mathrm{HbA} 1 \mathrm{c}$ ratio ranged widely from 2.0 to 4.0 in our subjects with stable glycemic control for at least one year, and the clinical meaning of the normal distribution of GA/HbAlc that we detected (Fig. 1) was unclear. We therefore performed multiple regression analysis to evaluate the correlation of the annual mean $\mathrm{GA} / \mathrm{HbA} 1 \mathrm{c}$ ratio with age, gender, BMI, and the estimated duration of diabetes for the subjects shown in Table 1. As shown in Table 3, BMI was negatively correlated with the GA/HbA1c ratio, suggesting that the production of GA may be relatively lower than $\mathrm{HbA} 1 \mathrm{c}$ formation in obese patients. When the subjects shown in Table 1 were classified into a low GA/HbA1c subgroup $(<2.9, \mathrm{n}=70)$ and a high $\mathrm{GA} / \mathrm{HbAlc}$ subgroup $(\geq 2.9, n=72)$, the average BMI and average annual mean $\mathrm{HbAlc}$ value were higher and the average mean GA value was lower in the low ratio group than in the high ratio group (BMI: $24.2 \pm 0.42$ vs. $21.9 \pm 0.41, \quad \mathrm{p}=0.0003 ; \quad \mathrm{HbA1c}: \quad 6.9 \pm 0.10 \quad$ vs. $6.5 \pm 0.09, p=0.002$; GA: $18.3 \pm 0.34$ vs. $20.8 \pm 0.39$, $\mathrm{p}<0.0001)$. However, study 1 was based on a small number of patients with a narrow range of values, and there was no analysis of albumin turnover or RBC lifespan, as well as no assessment of the interaction of daily blood glucose changes with GA or HbAlc levels. Furthermore, we did not assess plasma insulin level or the severity of insulin resistance. Thus, further studies are required to elucidate the obesity-related mechanism and other possible factors affecting $\mathrm{GA}$ or $\mathrm{HbAlc}$ formation.

The GA/HbA1c ratio showed a rapid decrease with insulin treatment (Fig. 3), because of the more rapid de- 
Table 3. Multiple regression analysis of factors related to the $\mathrm{GA} / \mathrm{HbA} 1 \mathrm{c}$ ratio

\begin{tabular}{lccr}
\hline \multicolumn{1}{c}{ Variable } & Partial regression coefficient & 95\% CI & $\mathrm{p}$ \\
\hline Age (yo) & -0.0022 & $-0.0093 \sim 0.0049$ & 0.5492 \\
Gender $(0: \mathrm{M}, 1: \mathrm{F})$ & 0.0196 & $-0.1326 \sim 0.1719$ & 0.7986 \\
BMI $\left(\mathrm{kg} / \mathrm{m}^{2}\right)$ & -0.0533 & $-0.0769 \sim-0.0297$ & $<0.0001$ \\
Estimated duration of diabetes $(\mathrm{yr})$ & -0.0023 & $-0.0115 \sim 0.0069$ & 0.6238 \\
\hline
\end{tabular}

crease of GA than HbA1c during the initial 8 weeks of therapy. The slight increase of the $\mathrm{GA} / \mathrm{HbAlc}$ ratio from 8 to 16 weeks may have been due to the more marked decrease of $\mathrm{HbAlc}$ than GA after 8 weeks of therapy. However, it remains unclear why GA/HbA1c ratio was higher in patients with untreated hyperglycemia than during the well-controlled state. It is interesting to speculate as to whether hyperglycemia itself, insulin deficiency, or insulin resistance affects albumin turnover or the RBC lifespan. Regarding the effect of insulin on albumin metabolism, a previous study showed that albumin synthesis was decreased in insulin-deficient type 1 diabetic patients [9]. A recent study demonstrated that the albumin synthesis rate (measured by an in vivo tracer method) did not differ between normoalbuminuric patients with mild type 2 diabetes and non-diabetic control subjects, while an acute insulin load during a euglycemic hyperinsulinemic clamp study increased albumin synthesis in both diabetics and controls [10]. These reports raise the possibility that insulin deficiency may increase GA formation through the down-regulation of albumin synthesis and prolongation of the half-life of this protein, while insulin resistance and compensatory hyperinsulinemia may decrease GA formation through the upregulation of albumin metabolism. Regarding the RBC lifespan, insulin may also influence erythropoiesis [11], while an increase of $\mathrm{Hb}$ and the RBC count has been observed in subjects with the insulin resistance syndrome [12] or metabolic syndrome [13]. Although these reports suggest that GA and $\mathrm{HbAlc}$ may be affected by plasma insulin level and insulin resistance through influences on albumin metabolism or erythropoiesis, direct information about whether these factors actually modify the formation of GA or HbAlc in diabetic patients has not been obtained. Therefore, it will be necessary to clarify these points in future, as well as investigating other possible influences (such as hyperglycemia itself or genetic factors) on GA or $\mathrm{HbAlc}$ formation. Unlike study 1 , we could not evaluate the distribution of the $\mathrm{GA} / \mathrm{HbA} 1 \mathrm{c}$ ratio at each point in study 2 , because the results were based on a small num- ber of patients and the absolute values of GA and $\mathrm{HbA} 1 \mathrm{c}$ in each patient were different.

GA has generally been considered as a short-term marker of glycemic control because of the short halflife of albumin, but there have been no reports about the changes of GA, HbAlc, and the GA/HbAlc ratio during improvement of glycemic control. The rapid decrease of GA seen in the present study reflects the faster turnover of plasma albumin than that of RBC. Thus, we can use GA as a sensitive marker for detecting early improvement of glycemic control when starting or modifying the treatment of diabetes, while HbAlc is a marker reflecting overall glycemic control for several months. We have often observed that GA increases prior to $\mathrm{HbA} 1 \mathrm{c}$ in patients with deteriorating glycemic control, so we need to study such cases over time to further confirm the clinical significance of GA. However, we cannot precisely assess current glycemic state from the GA value, because individual factors (such as BMI and other unknown factors) might influence GA formation independently of glycemia. We should also keep in mind that it is not optimal to convert $\mathrm{GA}$ values to $\mathrm{HbAlc}$ values through division by 2.9 , because the $\mathrm{GA} / \mathrm{HbA} 1 \mathrm{c}$ ratio is widely distributed in patients with a stable glycemic state and it changes in the same patient with variation of glycemic control. Thus, it is necessary to individually assess the steadystate $\mathrm{GA} / \mathrm{HbAlc}$ ratio during stable good glycemic control for conversion between GA and $\mathrm{HbAlc}$, and an increase of the value from such a steady level may suggest deterioration of glycemic control.

In conclusion, the mean $\mathrm{GA} / \mathrm{HbA} 1 \mathrm{c}$ ratio was 2.9 in type 2 diabetic patients with stable glycemic control, but the correlation between GA and HbAlc was weak and the $\mathrm{GA} / \mathrm{HbA} 1 \mathrm{c}$ ratio ranged widely from 2.0 to 4.0. GA decreased more rapidly than $\mathrm{HbA} 1 \mathrm{c}$ as glycemic control improved, and the $\mathrm{GA} / \mathrm{HbA} 1 \mathrm{c}$ ratio was higher in the hyperglycemic state than when diabetes was well-controlled. These results suggest that GA may be a useful marker for detecting short-term changes of glycemic control during treatment. 


\section{References}

1. Rohlfing CL, Wiedmeyer HM, Little RR, England JD, Tennill A, Goldstein DE (2002) Defining the relationship between plasma glucose and HbAlc: analysis of glucose profiles and HbAlc in the Diabetes Control and Complications Trial. Diabetes Care 25: 275-278.

2. American Diabetes Association (2004) Test of glycemia in diabetes. Diabetes Care 27 (Suppl 1): S90-S93.

3. Kawasumi M, Tanaka Y, Uchino H, Shimizu T, Tamura Y, Sato F, Mita T, Watada H, Sakai K, Hirose T, Kawamori R (2006) Strict glycemic control ameliorates the increase of carotid IMT in patients with type 2 diabetes. Endocr J 53: 45-50.

4. Dolhofer R, Wieland OH (1980) Increased glycosylation of serum albumin in diabetes mellitus. Diabetes 29: 417-422.

5. Iberg N, Flückiger R (1986) Nonenzymatic glycosylation of albumin in vivo. J Biol Chem 261: 1354213545.

6. Tahara Y, Shima K (1995) Kinetics of HbA1c, glycated albumin, and fructosamine and analysis of their weight functions against preceding plasma glucose level. Diabetes Care 18: 440-447.

7. Shima K, Abe F, Hitota M, Yano M, Yamamoto Y, Uchida T, Noguchi K (1988) High-performance liquid chromatographic assay of serum glycated albumin. Diabetologia 31: 627-631.

8. Kouzuma T, Usami T, Yamakoshi M, Takahashi M,
Imamura S (2002) An enzymatic method for the measurement of glycated albumin in biological samples. Clin Chim Acta 324: 61-71.

9. De Feo P, Gaisano M, Haymond MW (1991) Differential effects of insulin deficiency on albumin and fibrinogen synthesis in human. J Clin Invest 88: 833-840.

10. Tessari P, Kiwanuka E, Millioni R, Vettore M, Puricelli L, Zanetti M, Gucciardi A, Tosolini M, Cogo P, Carnielli V, Tiengo A, Barazzoni R (2006) Albumin and fibrinogen synthesis and insulin effect in type 2 diabetic patients with normoalbuminuria. Diabetes Care 29: 323 328.

11. Miyagawa S, Kobayashi M, Konishi N, Sato T, Ueda K (2000) Insulin and insulin-like growth factor I support the proliferation of erythroid progenitor cells in bone marrow through the sharing of receptors. Br J Haematol 109: 555-562.

12. Barbieri M, Ragno E, Benvenuti E, Zito GA, Corsi A, Ferrucci L, Paolisso G (2001) New aspects of the insulin resistance syndrome: impact on haematological parameters. Diabetologia 44: 1232-1237.

13. Mardi T, Toker S, Melamed S, Shirom A, Zeltser D, Shapira I, Berliner S, Rogowski O (2005) Increased erythropoiesis and subclinical inflammation as part of the metabolic syndrome. Diabetes Res Clin Pract 69: 249-255. 